This item was submitted to Loughborough's Research Repository by the author.

Items in Figshare are protected by copyright, with all rights reserved, unless otherwise indicated.

\title{
The full circle: enhancing feedback to students
}

PLEASE CITE THE PUBLISHED VERSION

http://dx.doi.org/10.21125/inted.2016

PUBLISHER

(C) IATED

\section{VERSION}

AM (Accepted Manuscript)

\section{PUBLISHER STATEMENT}

This work is made available according to the conditions of the Creative Commons Attribution-NonCommercialNoDerivatives 4.0 International (CC BY-NC-ND 4.0) licence. Full details of this licence are available at: https://creativecommons.org/licenses/by-nc-nd/4.0/

\section{LICENCE}

CC BY-NC-ND 4.0

\section{REPOSITORY RECORD}

Bamforth, Sarah E., Glynis Perkin, and Graham C. Sander. 2019. "The Full Circle: Enhancing Feedback to Students". figshare. https://hdl.handle.net/2134/22739. 


\title{
THE FULL CIRCLE: ENHANCING FEEDBACK TO STUDENTS
}

\author{
Dr S. Bamforth, Dr G. Perkin, Prof. G. Sander \\ Loughborough University (UNITED KINGDOM)
}

\begin{abstract}
At Loughborough University, the School of Civil and Building Engineering commissioned the Centre for Engineering and Design Education to undertake a longitudinal study, over four years, to explore issues associated with feedback on assignments from both the staff and student perspective. This study was prompted by low feedback scores on the National Student Survey ${ }^{1^{*}}$ and initially explored the sources of students' dissatisfaction with feedback and their perceptions of what constitutes feedback. In later years the study was broadened to explore how students use their feedback and the impediments to this. The findings of the study have influenced the feedback strategy and practice within the School with clear guidance given to staff, training provided to students and the introduction of enhanced feedback quality monitoring processes. This paper reports on the fourth year of the study, which goes full circle back to students' perception of effective feedback. The fourth year of the study seeks to explore, from the student perspective, whether the changes made have addressed the original issues raised by the students, whether they are satisfied with the quality of the feedback they now get and whether their expectations regarding feedback have changed. The study uses a combination of focus group discussions, and questionnaires to gather data from second and third year students who have been impacted most by the changes made within the School. This paper shares key findings from the study, including the impact that the practice changes have had on the general students' understanding of feedback and the changes in level of expectation of feedback, particularly with respect to the most engaged students.
\end{abstract}

Keywords: National Student Survey (NSS), feedback, higher education, student satisfaction.

\section{INTRODUCTION}

The findings presented in this paper are the culmination of a four-year longitudinal study (see Fig. 1), undertaken by the Centre for Engineering and Design Education (CEDE) at Loughborough University, which has researched issues relating to satisfaction with feedback and its use to inform future work from both the staff and student perspectives in its School of Civil and Building Engineering (CBE).

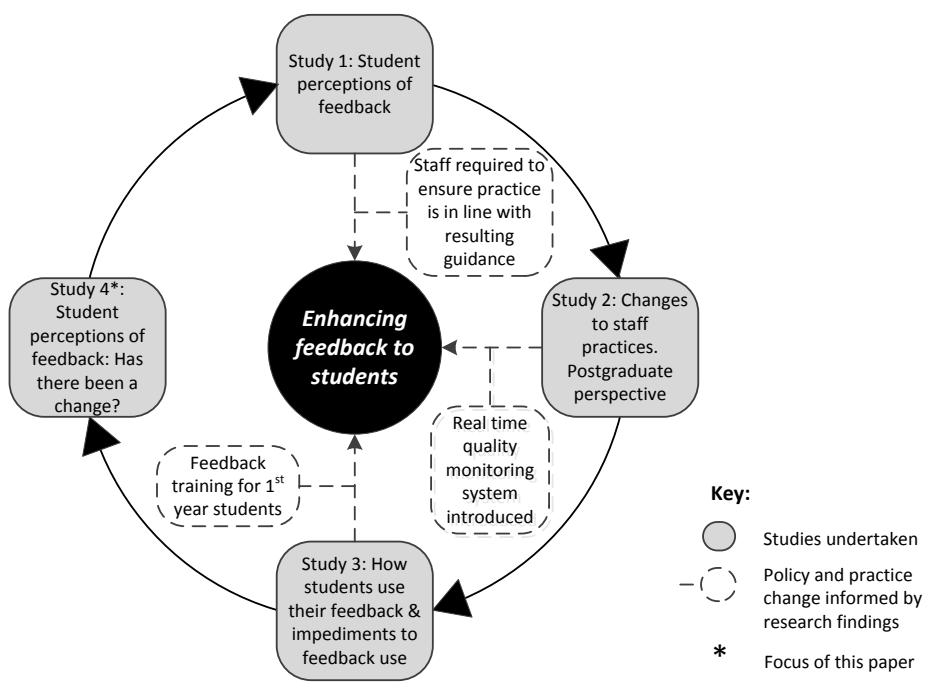

Fig. 1: Enhancing feedback to students - research studies, outcomes and outputs

\footnotetext{
${ }^{1}$ *An annual occurrence in UK institutions
} 
The first year of the study was undertaken during the 2011/2012 academic year and the research explored student perceptions of what constitutes feedback, their expectations regarding feedback and their views on the feedback they were already receiving. The findings from this research were published internally as a Digest of Effective Feedback Practice and also presented at the 2013 Higher Education Academy conference in the UK [1].

During the second year, a further study explored the expectations of taught postgraduate students; they were found to have a similar understanding of feedback and their expectations were aligned with those of undergraduates. Academic members of staff were also interviewed in order to determine what, if any, changes they had made to their feedback practice and their perceptions regarding students' use of feedback to feed forward. Staff recognised that the provision of feedback played a valuable role in enabling students to improve future coursework submissions and examination answers, which concurs with Gibbs and Simpson [2]. However, some members of staff were of the opinion that students were only interested in their grades and did not use feedback to improve subsequent work; this is supported to some extent by Wojtas [3]. This belief is also upheld by Crisp [4] who writes that: "...this study found only limited support for the idea that students respond to feedback by making changes which are consistent with the intent of the feedback received".

The third phase of the research was undertaken during the 2013/2014 academic year and investigated whether or not students in CBE were using the feedback they received to enhance future work and whether or not they experienced any situations that impeded them from using their feedback. It was determined that in most cases feedback needed to be timely and informative to enable students to feed forward into future work, which is in accord with Gibbs and Simpson [5]. There were also situations such as receiving feedback in a group setting that made students feel uncomfortable about viewing it directly upon receipt, see Bamforth, Perkin et al. [6]. Mulliner and Tucker [7] have undertaken research on staff and students perceptions of feedback practice and found there are differences in perception between staff and students relating to certain aspects of feedback such as students only being interested in grades. However, the findings showed that most students in the survey do read and act on feedback, which is in accord with Bamforth, Perkin et al. [6].

As a result of this research, the School has introduced a number of measures in order to enhance feedback quality for its students as shown in Fig 1. These include issuing to all staff a copy of the Digest of Effective Feedback Practice and requiring them to review their own practice to ensure that it matches the advice that is given in this guide; introducing a quality monitoring system whereby feedback quality for coursework being returned to students is checked; ensuring that each member of a group is provided with a copy of the feedback for all group coursework; a training session for first year students helping them to recognise the different forms of feedback available to them at Loughborough University and explaining how to get the most from their feedback.

However, four years since the initial research, the measures introduced by the School, to enhance feedback quality as a consequence of the findings, do not yet seem to be fully reflected in the National Student Survey feedback scores for the School. Whilst there may be a number of factors influencing this (including the fact that not all measures were introduced at the end of the first year of research) CEDE was asked to explore if issues identified in the initial research are still an issue for students; how satisfied students are with the quality of the feedback they now receive; and whether student expectations regarding feedback have changed. This paper focuses on the findings of a questionnaire survey used to investigate these issues during Semester 1 of the 2015/2016 academic year.

\section{BACKGROUND}

One reason for the increasing amount of research into student feedback and assessment in the UK is related to the introduction of the National Student Survey (NSS) in 2005. This survey is completed by final year undergraduates; it is the sections relating to assessment and feedback that have received lower scores than other areas of undergraduate study in UK universities [8], [9]. There are numerous publications relating to the provision of feedback, for example, [10], [11], [1], researching the effectiveness of feedback from the student perspective. However, there are far less publications that explore feedback issues from both the staff and student viewpoint, see, for example, [12], [13], [7].

Regarding feedback, Race [14] points out that it should have the following attributes:

- Timely

- Intimate and individual

- Empowering 
- Open doors not close them

- Manageable

Different attributes are also mentioned by other authors, for example, feedback should be appropriate [15]. Regarding negative aspects relating to feedback, Price et al. [16] found that students had difficulty deciphering hand written comments by some lecturers and stress that feedback must be legible.

That feedback should aid students to improve future work is inherent in The Concise Oxford English Dictionary's [17] definition of feedback which is specified as "information given in response to a product, a person's performance of a task, etc., used as a basis for improvement". Furthermore, it is well documented that feedback plays an important role in helping students to improve performance and learn from any earlier mistakes or omissions they may have made, see, for example, [18], [19], [20]. However, in order for students to use feedback to improve future work it must also be meaningful, for example, a comment such as "your style should be more academic" is unlikely to be helpful to the student [21]

CEDE's earlier research determined the importance of providing first year students with informative feedback as this will help them to improve prior to subsequent years of study when marks contribute to degree classifications; this is in accord with Yorke [22]. CEDE's earlier research also determined that students value feedback which is personal to them which agrees with Rae and Cochrane [11]. Following a three year study relating to student engagement with feedback, Price and Handley et al. [16] believe that "the learner is in the best position to judge the effectiveness of feedback, but may not always recognise the benefits it provides". This agrees with findings from the first year of CEDE's research which resulted in a recommendation that staff stress to students all the different forms of feedback they were being given.

Finally, the Higher Education Academy (HEA) has produced a feedback toolkit for staff wishing to improve the feedback they give to students and encourage the students to optimise the benefits of good feedback [23].

\section{RESEARCH METHOD}

This paper reports on the findings from the paper-based questionnaire surveys, originally it was planned to report only on data from $2^{\text {nd }}$ and $3^{\text {rd }}$ year students but it was felt that the inclusion of data for $1^{\text {st }}$ and final year students would give a more complete picture. The questionnaire approach enabled the study to sample quickly a larger number of students from the School, who are likely to be representative of a broader cross section of students with regards to engagement than would be anticipated from a focus group study. Past focus group studies within this School have tended to sample students who are more engaged with their studies. Having previously gathered rich data [24] in this area in 2011/12 through the use of the focus group method, the primary purpose for the current study is to gauge whether the previously identified issues and expectations are still current, a purpose for which the questionnaire method is appropriate [25]. Emerging issues will be followed up in Semester 2 by focus group meetings. The survey was administered by hand with three researchers attending a one hour timetabled coursework submission session. Students were approached and invited to take part in the study as they handed in their coursework. In this way only students who completely fail to engage in their studies (i.e. do not do their coursework) are not sampled. In total 200 students were scheduled to hand in coursework. It was not possible to approach all students due to large numbers arriving at the same time, however, of those asked to take part in the study only a few declined; 99 questionnaires were completed by students, indicating a high response rate.

Responses were received from both undergraduate students (92\%) and taught postgraduate students (8\%). Responses were received from students from all of the School's seven undergraduate programmes and two of the schools eight postgraduate programmes.

\section{FINDINGS AND ANALYSIS}

This section presents and analyses the major findings from the 2015/16 questionnaire survey and compares the results with the earlier research findings. 


\subsection{Are issues identified in the initial research still an issue for students?}

\subsubsection{Feedback on all marked work}

Two key issues identified in the 2011/12 study were that students wanted feedback on their examinations and Part A students wanted feedback on all their marked work, even though their performance in the first year does not contribute to their degree classification.

For the current $2015 / 16$ study $39 \%$ of the students surveyed said yes, there are instances with their marked work where they would like but do not currently receive feedback (Table 1). Elaborated responses from the surveyed students indicate that some students do not recognise model solutions as feedback and that some would like the feedback in a different format (detached from the work), suggesting that the extent of the problem is likely to be less than indicated by the numerical data. However, instances identified by students where they would like feedback include feedback on their examination answers and feedback on their individual industrial placement reports.

Table 1: Student responses to the question of whether there were instances on their marked work where they would like, but do not currently receive any feedback.

\begin{tabular}{||l|l|l||}
\cline { 2 - 3 } \multicolumn{1}{c|}{} & Yes & No \\
\hline \hline Undergraduate (All Parts) $n=83$ & $39 \%$ & $61 \%$ \\
\hline Part A students $n=14$ & $14 \%$ & $86 \%$ \\
\hline
\end{tabular}

The survey data also finds that less than $15 \%$ of Part A students identify times where they would like to have but do not receive feedback.

The findings for Part A students appear to suggest that the issue of not receiving feedback in Part A has largely been addressed for this group of students.

The finding that students are still raising the issue of not receiving feedback on their examinations may at first suggest that this issue has not been addressed. However, this may not be the case. It is standard practice for generic feedback to be made available on all examinations via the University's Virtual Learning Environment (VLE), therefore examination feedback should be available to all students. It may be that students:

1. do not value generic feedback in this instance,

2. are not content with the level of detail provided in the feedback,

3. or are not aware that it is available.

The idea that students are not valuing generic feedback on examination answers is seemingly supported by later findings in the study. Table 2 shows that undergraduate students rate group written feedback posted on the University's VLE as 'adequately helpful' and just 16\% (Fig. 2) of the surveyed students selected 'generic feedback' as being considered by them to be feedback.

A further area identified where some students would like feedback is on their year in industry reports. This is despite the fact that this report is a 'pass or fail' report that does not contribute to their degree classification but is cited on their degree certificate as a Diploma in Industrial Studies. These findings may indicate that students are becoming more conscious of feedback and expectations are rising, expecting feedback in areas where traditionally it has not been considered necessary.

Table 2: Student perspective on the helpfulness of different forms of feedback (2015 and 2011)

\begin{tabular}{|l|c|c|}
\hline \multicolumn{1}{|c|}{ Student perspective on the helpfulness of the following forms of feedback } & $\begin{array}{c}\text { Average } \\
\text { Likert value } \\
(5=\text { very } \\
\text { helpful })\end{array}$ \\
\cline { 2 - 3 } & 2015 & 2011 \\
\hline $\begin{array}{l}\text { Individual verbal feedback - specifically on your coursework. E.g. a discussion with your } \\
\text { tutor about how you did in your project and how you could improve it. }\end{array}$ & 4 & 5 \\
\hline $\begin{array}{l}\text { Group verbal feedback -the lecturer talks for 5 minutes at the start of a lecture about how } \\
\text { the class generally did in the coursework including common errors. }\end{array}$ & 3 & 3 \\
\hline
\end{tabular}




\begin{tabular}{|l|c|c|}
\hline $\begin{array}{l}\text { Group written feedback - the lecturer posts on Learn [VLE] general comments about how } \\
\text { the class has performed in the assignment including areas for improvement. }\end{array}$ & 3 & 3 \\
\hline Individual written feedback - short comments written throughout your coursework. & 4 & 3 \\
\hline $\begin{array}{l}\text { Individual written feedback - a mark sheet is included at the front of your coursework, } \\
\text { showing marks only for how you performed for specific elements in the coursework e.g. } \\
\text { drawings - 50\% References 60\% }\end{array}$ & 4 & 3 \\
\hline $\begin{array}{l}\text { Individual written feedback - a mark sheet is included at the front of your coursework, } \\
\text { showing statements which are ticked if they apply to your coursework. E.g. "describe and } \\
\text { provide sketches of the failure mode } \square \text { " }\end{array}$ & 4 & 3 \\
\hline $\begin{array}{l}\text { Individual written feedback - a mark sheet is included at the front of your coursework, } \\
\text { showing the element being marked and comments about how you performed in this area } \\
\text { e.g. Quality of results - "you should have taken multiple gauge readings to decide on the } \\
\text { average head over the weir". }\end{array}$ & 4 & 5 \\
\hline $\begin{array}{l}\text { Individual written feedback - a mark sheet is included at the front of your coursework, } \\
\text { element being marked, grade and a comment e.g. Explanation of the building's } \\
\text { background - B - "a concise but helpful overview of the building". }\end{array}$ & 4 & 4 \\
\hline
\end{tabular}

\section{Chart showing percentage of respondents who consider each of these to be feedback}

Model answers

Computer generated feedback on computer based tests

After marking, comparing your work to the specimen work

Informal conversations with your lecturer about your performance

Generic debriefing on Learn [VLE]

Generic whole class assignment debriefing

An overview of features of the best and worst coursework handed in by the class

Assesssment criteria and grade descriptors showing what is expected for each grade

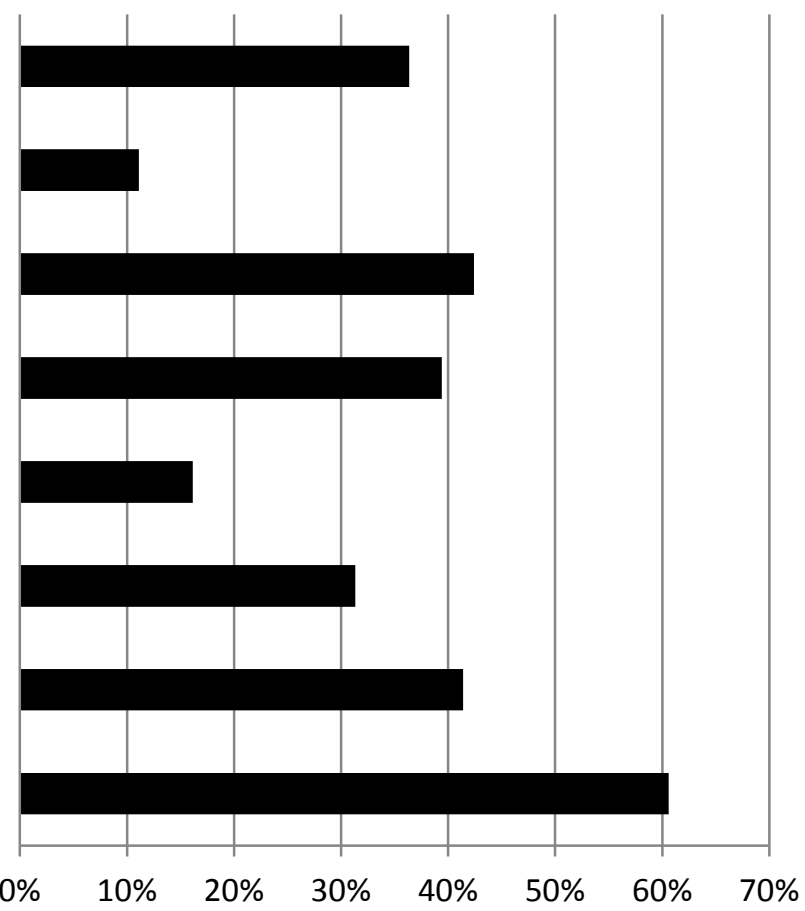

Percentage of respondents identifying each option as a source of feedback

Fig. 2: Percentage of respondents who consider each option as a source of feedback

\subsection{Are students happy with the quality of feedback and have expectations changed?}

The findings from the original focus group research in 2011/12 suggested that instances of feedback practice falling significantly below student expectations were relatively low. More prevalent issues tended to be where quality fell just short of expectation. 


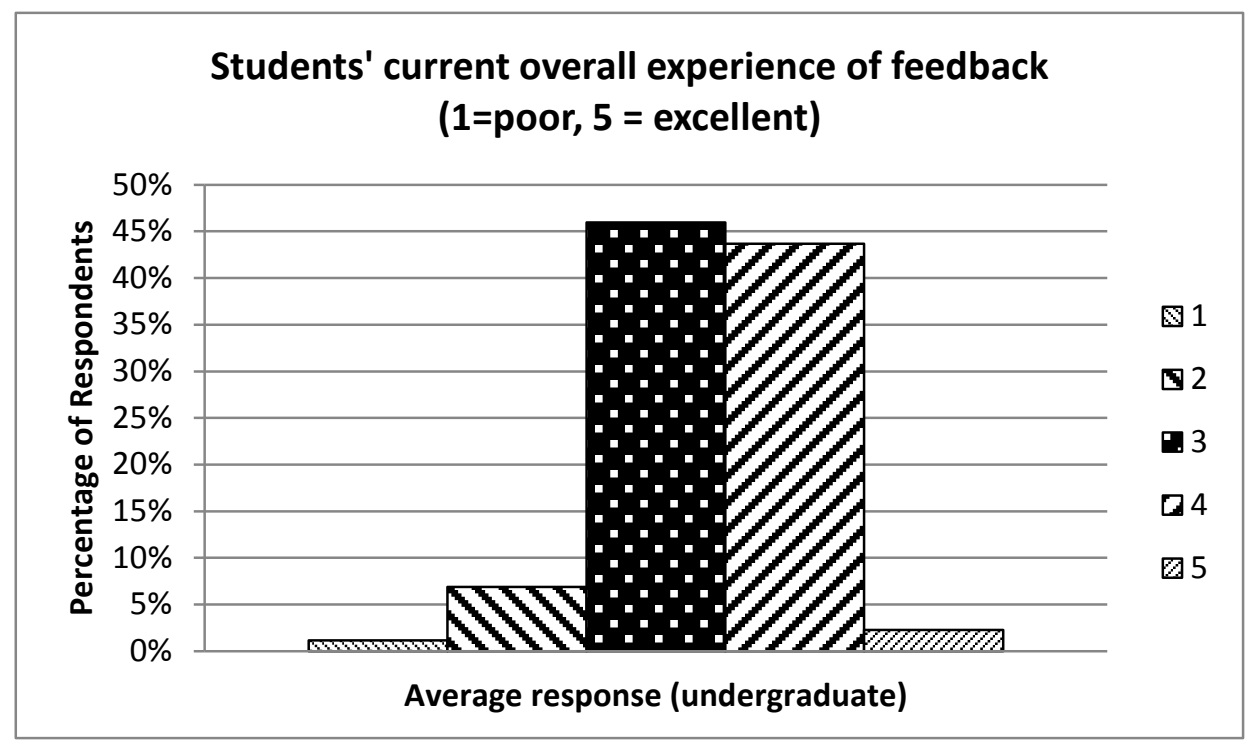

Fig. 3: Students' current overall experience of feedback

In the 2015/16 study $92 \%$ of undergraduate students rated their current overall experience of feedback as 3, 4 or 5 on a 5 point Likert scale where 1 is poor and 5 is excellent (see Fig. 3). Only 1\% rated their overall experience as poor. This suggests that the overall student experience of feedback within the School is a positive one.

In the current study, students were asked:

Where there had been instances of feedback falling below their expectations in the last 12 months:

a) How far below their expectations, for the majority of instances, had the quality fallen?

b) What were the issues?

The study found that where students had issues with feedback, in the vast majority of cases feedback quality only fell moderately below their expectation (89\% Moderately or slightly). This finding is in line with the findings of the initial study and suggests that in the main, students are happy with the quality of the feedback and that where they have issues these tend to be ones where feedback quality falls just short of their expectations.

The survey found that, where students perceived quality problems with their feedback, the two most cited issues were "too little detail", and "return took longer than 3 weeks" (Three weeks is the specified standard within the School). When questioned about how many modules were affected the modal average response was just one or two modules, suggesting that this is not a widespread problem.

In the 2011/12 research, students identified that they would rate feedback as good if it told them what they got right, what they got wrong and provided details on how to improve. The feedback quality monitoring system implemented by the School ensures that feedback to a student meets the Schools specified standard, a standard that was set using the findings of the 2011/12 research. The finding that students want more detail in their feedback suggests that School and student perceptions of 'appropriate level of detail in feedback' may be misaligned; with student expectations higher than those of the school. Given that School expectations of feedback detail are grounded in the findings of the 2011/12 study suggests that expectations may have risen. Whether these expectations are reasonable or can be realistically met with current resources is another question.

After insufficient detail, the second most cited reason for undergraduate students in the current study being unhappy with the quality of their feedback was that its return took more than three weeks. Compared to the 2011/12 study, where students reported that generally promptness was not a problem and they were more concerned about coursework being: returned in time to be useful for other work rather than it being returned within the 3 week deadline may suggest that there is an issue. Is the finding of the current study an indication that there are pieces of coursework being returned after the 3 week deadline? Follow up research within the Schools indicates that instances of coursework being returned later than 3 weeks are rare. The School feedback monitoring system shows that there were instances in the last 12 months where coursework was returned to students later than three 
weeks. All were due to staff illness. The instances of late coursework identified by 49 students in the study are likely to be due to these four staff illnesses, suggesting that this is not a genuine issue in the School as there were justifiable reasons. Of concern is the finding that despite the fact that all four staff apologised in advanced and communicated to students that the marked work would be returned late and the reason for this, students are still identifying these circumstances as falling below their expectations. In the 2011/12 study students indicated that they accepted late return times as long as staff communicated with students. Have student attitudes to late return due to illness changed and if they have, should this unrealistic expectation to be challenged rather than accepted?

\subsection{Has student understanding of feedback changed?}

The 2015/16 survey asked students to identify the features that make feedback good. For the responding students (both undergraduate and postgraduate) these three elements (what they got right, what they got wrong and provided details on how to improve) featured highly with over 59\% identifying them as important (see Table 3). However, other key features that students identified in the current study as very important were: feedback being returned within 3 weeks and in time for it to feed into other coursework; that the feedback points out where it is relevant to future work; that it shows the marking criteria used and that it contains individual feedback. The School, through its requirements and quality monitoring system, requires that all these elements, including the additional features identified by the 2015/16 students, are provided to students. For example it is a School requirement that Marking Criteria and corresponding weightings are provided in the coursework brief.

Table 3: Features of feedback that respondents identify as making feedback 'good'

\begin{tabular}{|l|c|}
\hline \multicolumn{1}{|c|}{ Feature } & $\begin{array}{c}\text { \% of respondents } \\
\text { selecting this feature }\end{array}$ \\
\hline Tells me what I got wrong & $73 \%$ \\
\hline Provides detail on how to improve & $72 \%$ \\
\hline Returned within 3 weeks & $69 \%$ \\
\hline Explains why it is wrong or right & $67 \%$ \\
\hline Returned in time to feed into other coursework & $63 \%$ \\
\hline Tells me what I got right & $59 \%$ \\
\hline Provides individual feedback & $58 \%$ \\
\hline Shows the marking criteria used & $56 \%$ \\
\hline Points out where it is relevant to future work & $49 \%$ \\
\hline Makes you feel you can discuss it with the lecturer & $46 \%$ \\
\hline Focuses on ALL the things that you need to address, large and small & $44 \%$ \\
\hline Shows the weighting of the marking criteria & $40 \%$ \\
\hline Typed & $35 \%$ \\
\hline When I get my own copy of the feedback on a group coursework & $35 \%$ \\
\hline Provided in a format I can revisit & $33 \%$ \\
\hline Focuses on 1 or 2 significant things that you need to address & $25 \%$ \\
\hline Handwritten & $21 \%$ \\
\hline Provides generic feedback which I can then relate to my work & $21 \%$ \\
\hline
\end{tabular}

The 2011/12 study found that feedback type is not critical if students can extract the relevance of the feedback to themselves, however when given a choice students prefer individual feedback. The findings shown in Table 2, suggest that that the students sampled in the 2015/16 study also prefer individual feedback but do find other types of feedback adequately helpful.

The 2015/16 findings shown in Fig.2 presents a mixed picture. Assessment criteria and grade descriptors were considered to be a source of feedback by $61 \%$ of the surveyed students. This is a welcome surprise as the 2011/12 study found that the students in that study, although valuing these features when shown them, did not necessarily understand these terms (assessment/marking criteria) when they came across them. This suggests that in the area of assessment criteria at least, student understanding may be growing. Of concern is the suggestion that over $70 \%$ of students may not consider key forms of feedback commonly used by staff, to be feedback. For example: generic debriefings on the VLE, generic whole class assignment debriefings and computer generated 
feedback on computer based tests. Even model answers were considered to be a source of feedback by $36 \%$ of the students sampled. These findings are seemingly at odds with those presented in Table 2; responding students rate generic feedback as adequately helpful but do not consider it to be a source off feedback. What does this contradiction mean for the National Student Survey?

These findings may indicate that student understanding of feedback has grown slightly in the area of assessment criteria but narrowed for other sources of feedback, with a strengthening preference for individual feedback.

\section{CONCLUSIONS}

The findings of the study indicate that gains have been made in addressing some of the issues identified in earlier research, in particular with regard to Part A students. However, the data appears to suggest, with the exception of assessment criteria and grade descriptors, a narrowing understanding and appreciation of what students recognise as feedback. Standard feedback mechanisms used by staff, such as generic feedback on the VLE and model solutions are not recognised as a source of feedback by over $70 \%$ of the students surveyed.

It would appear that student expectations of feedback are rising, with students wanting more detail in their feedback and for their feedback to be individual to them. Yet tolerance for human frailty, such as illness delaying the return of mark work (which was evident in the 2011/12 study), appears to be falling.

As feedback provision continues to be enhanced there is the possibility that student expectations will also rise, suggesting that it may be vital to work with students both to understand and to manage expectations to ensure that they are reasonable and realistic.

\section{ACKNOWLEDGEMENTS}

Special thanks to:

James Bacon, Placement Intern in CEDE, for assistance with distribution of the questionnaires and for contributing to the analysis of the raw data.

Alicia Pegg, Graduate Intern in CEDE, for assistance with distribution of the questionnaires

Caroline Neale, Executive Officer in CBE, for detailing the School's feedback policy

Staff in the Student Support Office for accommodating the authors at the coursework hand-in session.

\section{REFERENCES}

[1] Bamforth, S., Perkin, G. \& Glass, J. (2013) Effective Feedback from the Student Perspective. Higher Education Academy, York, UK.

[2] Gibbs, G. \& Simpson, C. (2004) Conditions under which assessment supports students' learning. Learning and Teaching in Higher Education, 1, (1) pp3-31.

[3] Wojtas, O. (1998) Feedback? No, just give us the answers. Times Higher Education Supplement, September 25th 1998. Available at: https://www.timeshighereducation.com/news/feedback-no-just-give-us-theanswers/109162.article [Accessed on 19 January 2016]

[4] Crisp, B.R. (2007) Is it worth the effort? How feedback influences students' subsequent submission of assessable work. Assessment and Evaluation in Higher Education, 32, (5), pp571-581.

[5] Gibbs, G. \& Simpson, C. (2004) Does your Assessment Support your Students' Learning? Centre for Higher Education Practice, Open University, UK. Available at: http://citeseerx.ist.psu.edu/viewdoc/download?doi=10.1.1.201.2281\&rep=rep1\&type=pdf [Accessed on 6 January 2016]

[6] Bamforth, S., Perkin, G. \& Glass, J. (2015) Feedback on student assignments: are there impediments to using feedback to feed forward? Paper presented at INTED2015 Conference: 
9th International Technology, Education and Development Conference, 2nd - 4th March 2015, Madrid.

[7] Mulliner, E. \& Tucker, M. (2015) Feedback on feedback practice: perceptions of students and academics. Assessment and Evaluation in Higher Education. Available at: http://www.tandfonline.com/doi/full/10.1080/02602938.2015.1103365 [Accessed on 22 December 2015]

[8] Buckley, B. (2011) National Student Survey: Analysis of national results for 2011. Higher Education Academy, York, UK. Available at:

https://www.heacademy.ac.uk/sites/default/files/NSS_report_2011_FINAL.pdf [Accessed on 20 January 2016]

[9] Unistats web site. Information available at: https://unistats.direct.gov.uk/ [Accessed on 14 January 2016]

[10] Poulos, A. \& Mahony, M.J. (2008) Effectiveness of feedback: the students' perspective. Assessment and Evaluation in Higher Education 33, (2) April 2008, pp143-154.

[11] Rae, A.M. \& Cochrane, D.K. (2008) Listening to students: How to make written assessment feedback useful. Active Learning in Higher Education 9, (3) pp217-230.

[12] Beaumont, C., O'Doherty, M.O. \& Shannon, L. (2008) Staff and Student Perceptions of Feedback Quality in the Context of Widening Participation. The Higher Education Academy, York.

[13] Di Costa, N. (2010) Feedback on Feedback: Student and Academic Perceptions, Expectations and Practices within an Undergraduate Pharmacy Course. Paper presented at the ATN Assessment Conference held at the University of Technology Sydney in November 2010. Available at: https://www.uts.edu.au/sites/default/files/DiCosta.pdf [Accessed on 4 January 2016]

[14] Race, P. (2001) Using feedback to help students to learn. HEA, York, UK. Available at: http://www.saide.org.za/sites/default/files/course_design/Race\%2034\%20Using_feedback.pdf [Accessed on 4 January 2016]

[15] Mory, E.H. (2004) Feedback Research Revisited. In D.H Jonassen (Ed.), Handbook of Research on Educational Communications and Technology, pp745-783. Lawrence Erlbaum, Mahwah, NJ, USA.

[16] Price, M., Handley, K., Millar, J. \& O'Donovan, B. (2010) Feedback: all that effort, but what is the effect? Assessment and Evaluation in Higher Education 35 (3) pp277-289.

[17] Soanes, C. \& Stevens, A. (Eds.) (2006) Concise Oxford English Dictionary (eleventh edition). Oxford University Press, Oxford, UK.

[18] Brown, S. \& Knight, P. (1994) Assessing Learners in Higher Education. Kogan Page, London, UK.

[19] Hounsell, D. (2003) Student Feedback, Learning and Development. Open University Press, Buckingham, UK.

[20] Knight, P. \& Yorke, M. (2003) Assessment, learning and employability. Society for Research into Higher Education, Open University Press, Maidenhead, UK.

[21] Woodward-Kron, R. (2004) 'Discourse communities' and 'writing apprenticeships': An investigation of these concepts in undergraduate education students' writing. Journal of English for Academic Purposes, 3, (2) pp139-161.

[22] Yorke, M. (2002) Academic failure: a retrospective view from non-completing students. In Failing students in higher education, M. Peelo \& T. Wareham, (Eds). Society for Research into Higher Education, Open University Press, Maidenhead UK.

[23] Higher Education Academy (2013) HEA Feedback Toolkit. HEA, York, UK. Available at: https://www.heacademy.ac.uk/sites/default/files/resources/feedback_toolkit_whole1.pdf [Accessed on 4 January 2016]

[24] Cohen, L., Manion, L \& Morrison, K (2000) Research Methods in Education. RoutledgeFalmer, London, UK. 
[25] Sapsford, R. (1999) Survey Research, SAGE Publications Ltd., London, UK. 